\title{
Violencia ecológico-ambiental y modernización económica en Colombia: una mirada a Libro de signos (1930) de León de Greiff
}

\author{
Juan Esteban Villegas-Restrepo ${ }^{1}$
}

Resumen. Tomando como punta de lanza las dinámicas modernizantes adoptadas por Colombia entre 1920 y 1940, este trabajo lleva a cabo una lectura ecocrítica, esto es, atenta a las relaciones que literatura y el mundo natural, de algunos de los poemas de Libro de Signos (1930) de León de Greiff. Una lectura de esta índole, cómo bien habremos de mostrar, posibilitaría dinamitar la concepción, casi siempre antropocéntrica, que se ha tenido sobre el fenómeno de la violencia en el país. Ello, a su vez, permitiría inscribir la temática de la violencia ecológico-ambiental en el amplio espectro de violencias sucesivas que ha sufrido el mismo a lo largo de su historia republicana.

Palabras clave: León de Greiff; poesía; violencia ecológica y ambiental; Colombia; siglo XX.

\section{[en] Eco-Environmental Violence and Economic Modernization in Colombia: a Look at León de Greiff's Libro de signos (1930)}

\begin{abstract}
Taking as a starting point the modernizing dynamics adopted by Colombia between 1920 and 1940, this work carries out an ecocritical reading, that is, a reading attentive to the relationships between literature and the natural world, of some of the poems contained in León de Greiff's Libro de signos (1930). As we will show, a reading of this kind would give us the possibility of atomizing the almost always anthropocentric conception that we've had in the country on the phenomenon of violence. This, in turn, would allow us to inscribe the topic of ecological and environmental violence in the broad spectrum of successive violences that the country has experienced throughout its republican history.
\end{abstract}

Keywords: León de Greiff; poetry; ecological and environmental violence; Colombia, $20^{\text {th }}$ century.

Cómo citar: Villegas-Restrepo, J.E. (2020) Violencia ecológico-ambiental y modernización económica en Colombia: una mirada a Libro de signos (1930) de León de Greiff, en Anales de Literatua Hispanoamericana 49, 367-378.

A partir de 1920 las dinámicas de la economía colombiana se vieron fuertemente alentadas por el florecimiento del mercado del café, la caña de azúcar, el petróleo y la minería, al igual que por el constante flujo de capital estadounidense que llegaba al país en calidad de préstamo y reparo por la pérdida del canal de Panamá. Con todo y la guerra con Perú (1932-1933) y la crisis mundial que la Gran Depresión de 1929 significó para el capitalismo, los réditos que la llamada "Danza de los millones" trae consigo se ven rápidamente reflejados en obras públicas a un nivel tanto urbano como rural, corroborando, pues, que "el modelo primario exportador que prevaleció hasta los años treinta del presente siglo, fue la fase durante la cual la economía se integró a la dinámica capitalista mundial, asignándole un rol en la división internacional del trabajo, como exportador de materias primas" (Corredor 1992: 72).

Nuestra poesía, escindida entre el cansancio y el apego suscitados por la ampulosidad clasicista de un Guillermo Valencia (1873-1943), la pompa señorial de un Tomás Rueda Vargas (1879-1943) o el modernismo simbolista de un Eduardo Castillo (1889-1938), se adentra en la búsqueda de nuevas formas y lenguajes para dialogar con los cambios que se avizoran en el país. Dentro de los muchos grupos generacionales que irrumpieron en el panorama literario y cultural del país durante esta época, vale destacar 
a Los Nuevos ${ }^{2}$, grupo que debe su rotulación historiográfica a una revista homónima de la cual solo llegarían a publicarse cinco números en la Bogotá de 1925.

Como miembro, entonces, de dicho colectivo, y consciente de su labor renovadora, León de Greiff, tal y como lo corroboran libros suyos como Tergiversaciones (1925) o Libro de signos (1930), pareciera haber constatado que el panorama lírico nacional, tan atiborrado hasta ese momento de aves majestuosas, páramos inalcanzables, ríos cristalinos y valles vírgenes, no solo era anacrónico con respecto a las nuevas tendencias estéticas del momento, sino que también lo era con respecto a la realidad social, económica, ecológica y ambiental del país, tan marcadas todas ellas por el constante dominio y explotación del hombre, la naturaleza y sus múltiples recursos.

Guiados por dicha lectura, y tomando en cuenta las dinámicas de modernización que comienzan a manifestarse a partir de la década del veinte y los efectos de las mismas sobre la naturaleza y el hombre, valdría la pena considerar si la frecuencia pero también la manera en la que el tropo Hombre vs. Naturaleza es abordado en sus poemas a la larga constata que para De Greiff el hombre "ya no [era] una entidad cerrada respecto a esta totalidad compleja, sino un sistema abierto que goza[ba] de una relación de autonomía/dependencia organizativa en el seno de un ecosistema (Morin 2008: 31), y que la naturaleza había "deja[do] de ser algo desordenado, pasivo y amorfo para convertirse en una totalidad compleja" (Morin 2008: 31). De ser cierta nuestra intuición, la manera en que dicho tropo es tratado permitiría, por un lado, evidenciar el lento pero certero proceso de imbricación entre las esferas de la cultura y la naturaleza en su poesía y, por otro, demostrar que las diferentes representaciones estéticas de la naturaleza develan, quizás por primera vez en la tradición poética de comienzos de siglo XX, una verdadera conciencia ecológica.

Partiendo de los supuestos anteriores, y valiéndonos de los supuestos teóricos del llamado campo de la ecocrítica $^{3}$, este ensayo pretende llevar a cabo una lectura explicativa de algunos de los poemas de Libro de Signos (1930). Una lectura de esta índole, atenta a las relaciones que el discurso poético entabla con el mundo natural, posibilitaría dinamitar la concepción, casi siempre antropocéntrica, que se ha tenido sobre el fenómeno de la violencia en el país. Ello, a su vez, permitiría inscribir la temática de la violencia ecológica y ambiental en el amplio espectro de violencias sucesivas que ha sufrido el mismo a lo largo de su historia republicana.

León de Greiff (1895-1976) fue quizás el integrante más viejo de Los Nuevos. Se une el grupo a sus 30 años de edad. Su poesía, profundamente ecléctica, se resiste a cualquier intento de rotulación histórica o estética. Podría decirse además que, en sintonía con el de Luis Vidales y Luis Carlos López, su verso también destila humor, ironía, sátira y espíritu lúdico. Dicha heterogeneidad se debe mayormente al cosmopolitismo que el mismo de Greiff avizoró para su proyecto estético, un proyecto en donde es posible percibir una cierta simultaneidad de lo que a primera vista pudiera percibirse como no simultáneo. De ahí que, en dicho proyecto, como bien comenta Marco Ramírez Rojas en su tesis doctoral sobre el autor y su lugar en la tradición poética colombiana, subyazcan de manera paralela "el modernismo, los poetas simbolistas, la poesía medieval de juglares y trovadores, la poesía del Siglo de Oro, la presencia de lo nórdico, [...] el diálogo con la doble imagen de oriente - Oriente medio y el Oriente lejano" (2013: 7-8).

Como integrante de Los Nuevos y como exponente, por ende, de una tímida mas no por eso menos presente vanguardia poética, León De Greiff volcará su mirada a esa tradición poética que le antecede, pero lo hará no con el fin de adoptarla sino más bien de problematizarla, de exponer su anacronismo no solo estético sino también político e histórico, consciente, por ende, de que el discurso bucólico, tan en boga para aquel entonces en la poesía nuestra ${ }^{4}$, podría, al igual que el discurso pastoril, tanto "direct us toward the

${ }^{2}$ Conformada por políticos de ultraderecha, centro e izquierda como Augusto Ramírez Moreno (1900-1974) y los hermanos Alberto (1903-1990) y Felipe Lleras Camargo (1900-1986), respectivamente, el cronista Luis Tejada (1898-1924), los poetas León de Greiff (1895-1976), Rafael Maya (1897-1980), Germán Pardo García (1902-1991) y Luis Vidales (1904-1990), el novelista Jorge Zalamea (1905-1969), el dramaturgo Ciro Mendía (1892-1979), y el caricaturista Ricardo Rendón (1894-1931), dicha generación buscó "llevar al extremo sus ideas de partido y unirse, paradójicamente, pregonando la necesidad de avivar el enfrentamiento en el campo de las ideas" (Ardila Ariza 2013: 11-12).

${ }^{3}$ Entendida aquí como el campo de estudios que, según Mauricio Ostria (2011), "procura integrar las producciones textuales a un sistema mayor, distinto a las tradicionales series literarias, culturales e históricas" (10), esta, la ecocrítica, tiene, pues, como fin reflexionar sobre los posibles vasos comunicantes tanto éticos como estéticos que un texto literario podría llegar a entablar con la problemática ecológica-ambiental de un barrio, una ciudad, una vereda, una reserva, un cabildo, un departamento o un país cualquiera.

${ }^{4}$ Así parece considerarlo también el poeta y crítico literario colombiano Fernando Charry Lara cuando, en un célebre ensayo suyo sobre Los Nuevos, y con ello, sobre parte de la poesía escrita durante el segundo y tercer decenio del siglo XX, aduce que, para aquel entonces en la lírica nuestra, "no había concluido la infortunada herencia 'greco-latina', compañera inseparable de la pompa tribunicia y de la decoración modernista, que tenía en el viejo humanismo sólido antecedente. A la misma obra virgiliana, por ejemplo, podía acudirse para ennoblecer la visión bucólica de nuestra provincia" (1984: 637, el subrayado es nuestro). 
realm of physical nature, or [...] abstract us from it" (Buell 1995: 31). Aferrada a la primera de estas opciones, a la del posible acercamiento con la naturaleza ofrecido por el discurso bucólico, y contrario a lo que sus antecesores habían mostrado, la poesía greiffiana terminará batiéndose entonces entre lo mítico y lo desencantado, lo arcaico y lo actual, lo rural y lo urbano, lo idílico y lo realista, lo consolador y lo angustioso, lo pre-moderno (mayormente romántico) y lo vanguardista. Oscilación esta que en el fondo revela que, para el poeta antioqueño, entre ese pasado bucólico y provincial, en ocasiones libre de injerencia humana, y ese futuro cada vez más determinado por el dominio de la naturaleza y sus recursos a manos del hombre, yace un presente, o mejor aún, un mundo natural profundamente signado no solo por la modernización de comienzos de siglo XX, sino también por la Conquista, la Expedición Botánica y la Misión Corográfica. En suma, unas ecologías poscoloniales que requieren de un acercamiento distinto que, además de ontologizar la naturaleza, también la historice; un acercamiento ecopoético que dé paso, como sugiere Handley (2010) refiriéndose a las representaciones de la naturaleza que Alejo Carpentier ofrece en su novela Los pasos perdidos (1953), a "a sense of ecology [that] becomes both mimetic and poetic when art temporarily territorializes nature -as sign of value - but then renounces to its ability to subsume and capture it" (131-132).

Así pues, y a modo de apunte biográfico colateral, cabe recordar que entre 1926 y 1927 de Greiff ocupa el cargo de administrador de obras del Ferrocarril de Antioquia por el río Cauca, más específicamente en el municipio de Bolombolo, epicentro de dichas operaciones. Tal y como comentan Mattos et al. (2010), la construcción del ferrocarril en 1928 en los linderos del río Cauca, "fundó a Bolombolo como un puebloestación, de cruce de caminos y carreteras, de fondas y actividad mercantil, de encuentros de campesinos, arrieros y comerciantes del suroeste y de Medellín" (170).

En lo que a la región antioqueña respecta, es fundamental destacar que, hasta el advenimiento del ferrocarril en 1874, "los caminos eran, en su mayoría, trochas o senderos tallados en el paisaje y se reconocían por el cambio en la tonalidad de verde" (Londoño et al. 2014: 59, el subrayado es nuestro). Puerta del suroeste antioqueño, y con ello del eje cafetero colombiano, Bolombolo, necesitaba, pues, del ferrocarril para con ello dinamizar la economía cafetera. A la final son ellos, los sacos de café, los que hilvanan nuestra economía nacional con el mercado internacional; son ellos también quienes permiten la expansión de la lógica agro-capitalista, a través de la colonización, hacia nuevos territorios en el país (mayormente hacia el oriente); y son ellos los que proveen también las bases tanto económicas como sociales para la remoción de suelos y consiguiente creación de una malla vial, mayormente ferroviaria, que comunica regiones hasta ese momento lejanas para muchos (Machado 2001: 82-85). Dichos cambios vendrían a ser más evidentes a partir de la década de 1920, cuando se da rienda suelta, gracias a la bonanza producto de la ya mencionada "Danza de los Millones", de la expansión de la malla vial del ferrocarril y de la construcción y mejora de las diferentes carreteras regionales (Suárez Quirós 2014: 108) ${ }^{5}$.

Lector de su época, De Greiff no fue pues ajeno a las dinámicas de modernización económica que por aquel entonces se estaban dando en el suroeste antioqueño: el clima, la destrucción de la fauna y la flora, la reconfiguración de la topografía nacional, la realidad social de los mineros que laboran a orillas del Cauca, y más importante aún, su faceta transitoria de hombre de ciudad a hombre de campo, se dan cita en Libro de signos, y de manera más específica, en la sección titulada Música de Cámara y al Aire Libre: Segundo ciclo, país de Bolombolo 1926-1927. De ahí que lo que veamos primeramente en el universo poético greiffiano de esta sección sea un sujeto que, apuntalado tanto por el mito fundacional histórico del proyecto modernizador como por el mito fundacional estético vanguardista, se adentra en la naturaleza haciendo gala de su aura redentora. Como es de esperarse, la completa inmersión en el mundo natural es lo que le permitirá dialogar con ella a través de un sistema biótico y abiótico, complejo y diverso. Por eso, más que evidenciar de manera inmediata la concreción de las prácticas de explotación de la naturaleza por parte del hombre, las cuales veremos más adelante, "FANFARRIA EN SOL MAYOR (Odecilla estival)", primer poema aquí abordado, lo que hace es narrar el momento exacto de encuentro entre ambos:

1 Oh Bolombolo, país exótico y no nada utópico en absoluto! Enjalbegado de trópicos hasta donde no más! Oh Bolombolo de cacofónico o de ecolálico nombre onomatopéyico y suave y retumbante Oh Bolombolo!

5 Por aquí se atedia, en éste se atedia por modo violento la fantasía; monótono

5 “Si en 1885 la red ferroviaria solo llegaba a los 203 kilómetros, hacia 1914 ya era de 1.116" (Jaramillo 1998: 44). 
país de sol sonoro, de excesivas palmeras, de animalillos zumbadores, de lagartijas vivaces, de salamandras y camaleones, cigarras estridulantes, verdinegros sapos rugosos, y melados escorpiones.

(De Greiff 1975: 193)

La utopía edénica tan común a poetas anteriores a de Greiff pierde aquí toda vigencia: el país de Bolombolo, cual Arcadia desencantada, resulta monótono, tedioso, excesivo. De hecho, la construcción fonética misma de estas dos primeras estrofas, con énfasis en las 's', ' $z$ ' y ' $c$ ', contribuyen a ahondar más aún la existencia de "animalillos zumbadores", de vientos, de ráfagas, de chirridos estridentes. De ahí que el poeta antioqueño, satírico hasta la médula, enmarque su poema dentro de las dinámicas musicales del género de la fanfarria, consciente, a su vez, de que dicho término sirve no solo para aludir a un tipo de música de tinte pomposo, heroico y majestuoso que anuncia el encuentro con un algo o un alguien de gran importancia, sino también a una acción charlatana que busca apocar en vez de sublimar. Además, no es casual que De Greiff, como si se tratase entonces de una especie de armadura al principio del compás, dé inicio al poema con el contraste tajante entre tonalidades/expresiones altisonantes de rezagado romanticismo y agonizante modernismo como el "Oh Bolombolo, país exótico", y otras de tinte más vanguardista y desacralizante como el "y no nada utópico". El mensaje es claro: actitud irónica ante la actitud mesiánica del hombre de comienzos de siglo que se adentra en la selva buscando 'civilizar', pero actitud irónica también ante una naturaleza que, dada su belleza, su caos, su dinamismo, pone a la poesía y al proyecto modernizante contra las amarras. Gracias a ello es que la dinámica entre hombre y naturaleza logrará ir también más allá del simple intento de domesticación tanto estética como material por parte del hombre: permitirá entrever también la resistencia, la momentánea obstaculización que la naturaleza misma habrá de mostrar frente a dichos proyectos de dominio y explotación. Aquí queremos ser particularmente enfáticos, puesto que todo esto es lo que permitirá a De Greiff dinamitar, ya sí por completo, la oposición binaria entre Cultura vs Naturaleza, heredada de la Ilustración, y más importante aún, testimoniar el escalonamiento de la alienación del hombre con respecto a la naturaleza y la consciencia del mismo frente a dicho distanciamiento.

$\mathrm{Y}$ aquí hay que ser especialmente cuidadosos, porque este juego irónico de espejos, en primer lugar articulado con la escogencia del género musical y reafirmado luego con esa especie de armadura a comienzos del compás, servirá también para inscribir la poesía de De Greiff en la tensión aquella entre el mito fundacional estético de la vanguardia y el mito fundacional histórico de la modernización. No obstante, aquí la tensión no se dará por separado: el quehacer poético, es decir, el poema mismo, comenzará a operar como vehículo de afirmación y síntesis de ambos mitos: la historia como poema y el poema como historia; unión de la vida y el arte, el verso como visión y acción, el poema como máquina, el poeta como ingeniero.

Conforme a lo que hemos expuesto, estamos pues ante un sujeto que canta y desencanta la naturaleza. Tras experimentar el exceso, el ruido, y el colorido de un mundo natural que se desborda por doquier, que le resulta anodino, este, en un gesto de forzado elogio, finalmente constata que su poética representacional, que toma elementos prestados del barroco, de la música, el modernismo, el romanticismo, de la zoología, la botánica, la geología, entre otros, ha sido llevada hasta los límites; las variadas vegetaciones, topografías, climas y criaturas le obligan a tomar conciencia de su propia inhabilidad para describir lo que tiene ante sus ojos. Ya no es Bolombolo el vocablo de 'ecolálico nombre'; es él, el sujeto del poema mismo, quien da muestras ahora de ser portador de un lenguaje poético ecolálico, ecoico y residual de aquel que emite la naturaleza con su geografía, sus colores, temperaturas, sapos, palmeras, cigarras y escorpiones, imposibilitando, con ello, cualquier intento de aprehensión mimética. Viéndose así, falto de recursos, este no tiene opción alguna más que recurrir a su acervo cultural para con ello intentar, pero solo intentar, darle sentido a esa nueva realidad que, una vez filtrada por el sol, se vislumbra ante sus ojos:

10 Por aquí refractan, en éste refractan luces blancas,

y todo reverbera como innúmeras estatuas

de sal, o como una falange elefantina recamada

de pulidos escudos, o como las trompetas en la bárbara

marcha de los dioses que entran al Walhalla,

15 o como la carga

de coraceros de Ney en la planicie desolada!

Y reséncanse los prados de las colinas y llanadas

y de las vegas y lomas y abras,

e irradian los belígeros soles

20 dardos y flechas y virotes! (De Greiff 1975: 193) 
El referente bíblico que ofrecen las estatuas de sal, el histórico del ejército de la antigua ciudad egipcia de Elefantina y la escuadra uniforme del ejército de Michel Ney (1769-1815), mariscal de Francia, y el mitológico del Walhalla nórdico: todos ellos se quedan cortos al momento de dimensionar el poderío de un 'Sol mayor' que todo lo irradia, que todo lo reseca y marchita, que todo lo aglutina y unifica bajo su luz cegadora. Siguiendo a George B. Handley, la ecología, tal y como la presenta aquí De Greiff, es un "as a space of indeterminacy and instability [...] a dynamic space of change, imbalance, and even chaos" (Handley 2010: 119). Es por ello que este, consciente de dicho caos, introducirá a partir del vigésimo primer verso una especie de leitmotiv, cuya función, estructuralmente hablando, será la de dar cuenta, por lo menos en un principio, de un espacio de alternancia, de tranquilidad para el sujeto del poema, un espacio diametralmente opuesto al de las revoluciones agresivamente estivales de aquella naturaleza que se articulan en el resto del poema:

Y sólo en la noche la astral urdimbre

tiende su velo de Tánit inasible! (De Greiff 1975: 194)

Reminiscente del Novalis (1772-1801) de Himnos a la noche, y por medio suyo de una larga tradición romántica que ve en la noche el tiempo y el espacio de unión, de calma, de constatación poética por antonomasia, este leitmotiv es concebido por el sujeto del poema como tiempo y espacio de tranquilidad, contemplación y dominación poética que el día, con su fulgor estridente, con su desmesurada naturaleza, le niega. Se destaca por eso el uso del término urdimbre, sinónimo del hilo aquel que se extiende de izquierda a derecha sobre el tejido, y que al ser adjetivado con la palabra 'astral' permite una doble lectura: el hilo longitudinal como elemento constitutivo de una noche estelar que, entre tejido y tejido, sumerge al mundo todo en una oscuridad presente aunque inasible, pero también el hilo longitudinal como parte fundamental de un tejido, de una escritura lírica, de una poética romántica tan presente como inaprensible que solo puede ser hilvanada/escrita/leída durante la noche. Una vez concluida la noche, y la posibilidad poética que esta trae, la impetuosidad solar de aquel brioso y convulso país de Bolombolo no se hace entonces esperar:

Oh Bolombolo, país de tedio

badurnado de trópicos, país de tedio,

25 país que cruza el rio bulloso y bravo, o soñoliento;

país de ardores coléricos e inhóspites,

de cerros y montes

mondos y de cejijuntos horizontes

despiadados. País de vida aventurera. País de rutilantes playas de esmerilado cobre

30 -tortura de mis ojos zarcos y cuasi nictálopes-,

país de hastiados días y días turbulentos, y de noches

que alargan los recuerdos insomnes. (De Greiff 1975: 194)

Cabe resaltar la importancia que la dimensión corporal y material ha comenzado a cobrar en el poema. Ya no basta con decir, como en el quinto y sexto verso, que "se atedia por modo / violento la fantasía". Continúa siendo tedioso, es cierto, pero aquel país de Bolombolo se hace ahora palpable no solo en el ámbito de lo imaginativo, lo poético y lo fantástico, sino también en los "ardores coléricos e inhóspites (sic)" que este suscita en el cuerpo de quien lo habita, de quien lo transita. Más interesante todavía, por primera vez en lo que va corrido del poema, el sujeto del poema, en su afán por dar forma, por amansar estéticamente al mundo que yace ante su mirada, incorpora a su bagaje metafórico vocablos ya no de factura histórica, ni mitológica, ni bíblica: una expresión como "esmerilado cobre" invita a contemplar la inserción a dicho bagaje de un referente netamente orgánico y mineral.

¿A que podría deberse esto? ¿Por qué tal inserción de lo orgánico y lo mineral en un poema que un principio se mostraba más preocupado por la aprehensión puramente estética del mundo natural? Una posible manera de dar respuesta a este interrogante sería el yuxtaponer los dos planos espaciales que el poema nos brinda en estos versos: cabe notar que mientras que arriba se vislumbran los "cerros y montes / mondos y de cejijuntos horizontes / despiadados", agrestes, libres de todo adorno, de toda injerencia humana, abajo, en coexistencia con el trópico y el río soporífero, saltan a la vista unas orillas desgastadas, bruñidas por algo más que el sol: unas "rutilantes playas" de una tonalidad cobriza, de una constitución orgánica que, vista a primera luz, da entrever una cierta potencialidad de futura erosión que resulta incómoda y tortuosa a los ojos "zarcos y cuasi nictálopes" del sujeto del poema. 
Llegados a este punto cabría recordar que la industria minera, cuyos inicios se remontan a la Sociedad del Zancudo, creada en 1848 Antioquia por el magnate y político conservador José María Uribe Restrepo (Restrepo 1979: 46), contribuye a exacerbar más aun el 'ecocidio' en el país, y mayormente en Antioquia, epicentro de la misma. Treinta años después, con la creación de la Compañía minera de Antioquia en 1875, de la Escuela de Minas de Medellín en 1887 y de la Sociedad Minera del Suroeste en 1888, el sector minero logra implementar nuevas y más eficaces técnicas de extracción, tales como la draga (Molina 2011: 10-11). Pero es a partir de 1925 que "entran las nuevas tecnologías importadas al país - como lo fueron - los martillos perforadores neumáticos" (Gallo \& Márquez 2011: 38), herramientas estas que para 1931 son adoptadas por la Frontino Gold Mines "para abrir socavones, galerías y apiques" (38) que, sin duda alguna, terminaron teniendo efectos devastadores sobre la tierra y el ecosistema como tal. No extraña por ello que el sujeto del poema advierta la fuerte erosión de las orillas del río Cauca. Es cierto que el brillo propio de esta constitución orgánica le resulta molesto al sujeto del poema, pero le ofrece al mismo tiempo una cierta potencialidad estética. Estamos, para decirlo de otro modo, ante un sujeto del poema que transita desde lo trascendental hasta lo físico, ingresando, con ello, a una esfera relacional en donde la materialidad orgánica de lo no-humano adquiere una cierta vitalidad intrínseca, un posible valor poético.

Dentro del esquema de la teoría sociológica del Actor-Red esbozada por Michel Callon y Bruno Latour ${ }^{6}$, estas "rutilantes playas de esmerilado cobre", dada la capacidad de maniobra y proto-historización que tienen sobre la visión, sobre la cognición del sujeto del poema con relación al mundo natural, vendrían a ser consideradas como un 'actante', como un algo no necesariamente humano que, según Latour (1996), "something that acts or to which activity is granted by others [...] An actant can literally be anything provided it is granted to be the source of an action" (Latour 1997: 7). Nuestro énfasis en la importancia que el sujeto del poema les da a estas playas, y más importante aún, el lenguaje metafórico a través del cual este las incorpora a su visión de la naturaleza, no es fortuito. Profundamente enraizado en una visión ecocéntrica, De Greiff entiende que "the ethical aim becomes to distribute value more generously, to bodies as such" (Bennett 2010: 13).

No obstante, este instante de reconocimiento ontológico de la naturaleza es sucedido nuevamente por el ya aludido leitmotiv, por la pulsión de aprehensión puramente estética que este propicia, aunque con una variación:

Y sólo en la noche azul la astral urdimbre tiende su velo de Tánit, intangible.

(De Greiff 1975: 194, el subrayado es nuestro)

A diferencia del primero, que hilvana un tejido nocturno que alude a la noche, y con ello a una cierta poética romántica que, aunque inasible, se hace todavía presente, aquí lo que vemos es una gradual evaporación de los mismos, una sutil transición del ámbito de lo críptico al ámbito de lo "intangible", corroborando, pues, que tanto la noche como la poesía han sucumbido ya ante el brillo y la textura de una naturaleza cada vez más dinámica, menos presta a esa domesticación estética. El ensamble simultáneo de otrora entre mito fundacional estético y mito fundacional histórico se deshace por completo: ante la aparente imposibilidad del primero, solo el último, el histórico, queda en pie. Y con él, la confirmación explícita que la naturaleza está cada vez más próxima a la explotación:

Por aquí se atedia, en éste se atedia por modo

40

violento la fantasía: antitético Polo!,

paraíso apenas para el "farniente" y el ocio

del obtuso bolonio,

como del soñador... País de vida aventurera! Cosa de cine! Caza del oro!

(De Greiff 1975: 194, el subrayado es nuestro)

\footnotetext{
${ }^{6}$ Según Law (1994), "The provenance of actor-network theory lies in poststructuralism: the vision is of many semiotic systems, many orderings, jostling together to create the social. On the other hand, actor-network theory is more concerned with changing recursive processes than is usual in writing influenced by structuralism. It tends to tell stories, stories that have to do with the processes of ordering that generate effects such as technologies, stories about how actor-networks elaborate themselves, and stories which erode the distinction between the macro and microsocial" (18).
} 
De Greiff se vale de la selección lingüística de términos como "farniente" y "obtuso bolonio", sinónimo de necio, de ignorante, y de la consonancia silábica de este último y la palabra "ocio" para con ello aludir a esa figura de la holganza, la inactividad y el asueto por antonomasia que es el burgués moderno. Ante la imposibilidad de domesticación estética, el sujeto del poema pareciera centrarse ahora en esa otra domesticación, en la física y la instrumental, que ve en el oro, que ya no en el verso, su más apto vehículo de concreción. Por ende, la importancia de la alusión profética a ese Otro, representado en este caso por el oriental y el africano, y con ellos a esa maquinaria neocolonial próxima a ser instaurada:

¡Síntesis de los Saharas y summa de los Congos!

Monótono / país de sol sonoro. (De Greiff 1975: 194)

Con el aparato colonial ensamblado ya en el poema, el país de Bolombolo adquiere entonces un cierto carácter de prisión, de desdicha, de desamor para con la naturaleza:

Los días siguen idénticos, iguales, uniformes.

Las sienes agóstanse como flores

efímeras. Por mal de amores,

por mal de ausencia los corazones

$50 \quad$ cargan cadena en el penal de tus soles!

$\mathrm{Y}$ los recuerdos alargan las noches insomnes

hondas de silencio y de constelaciones! (De Greiff 1975: 194)

La referencia a las sienes y a los corazones terminan por constatar la centralidad de lo corporal, como antítesis a la dimensión metafísica de otrora, al momento de interactuar con el mundo natural: en el país de Bolombolo tanto las sienes de aquellos que lo observan y lo intentan poetizar, como las de aquellos que lo trabajan, que lo expolian, se 'agostan', se resecan como flores efímeras. Instante, fugacidad, ocasión: todo va y todo viene, el mañana es igual al hoy. Poco importa quien la trabaje hoy y quien mañana; de ahí la uniformidad de los días. Ahora bien, coincidimos con Marie Estripeaut-Bourjac (1999) cuando afirma que "el presente es el tiempo de Los Nuevos. Lo pueden controlar y les da la sensación de existir para sí mismos, de ser una conciencia y una entidad. La urgencia de presente que expresan corresponde a la inconsistencia de su pasado" (747). No obstante, y contrario a lo que dice Estripeaut-Bourjac, en De Greiff la disociación con dicho pasado no es tan rápida como uno esperase: el sujeto del poema, en su nicho nocturno, siente cómo las noches se alargan gracias a los recuerdos. Acabar con él, con el pasado, requerirá de un paso más. Requerirá que el acto poético, tal y como era concebido, que la astral urdimbre, inicialmente inasible y luego intangible, sea ahora y para siempre imposible:

Y sólo en la noche azul la astral urdimbre,

Sobre mi cansancio ilímite,

Tiende su velo de Tánit, imposible!

(De Greiff 1975: 194, el subrayado es nuestro).

Aquí debemos ser cuidadosos, porque es precisamente esta imposibilidad para nombrarla, para asirla poéticamente, lo que más adelante permitirá que la naturaleza deje de fungir solamente como decorado y comience a develarse ante el sujeto del poema como ente portador de un estatus ontológico ya no solo válido y dinámico, sino también apto tanto para la explotación material como para una nueva explotación estética. $\mathrm{O}$, dicho de otro modo, una vez extinguida toda posibilidad de aprehensión estética, el sujeto del poema, profundamente inmerso, pero al mismo tiempo desencantado del mundo natural, centra ahora su mirada en la vitalidad intrínseca de los elementos constitutivos de estas ecologías bolomboleñas. Y dicho reconocimiento dará cabida a que el hombre, consciente de la vitalidad de la naturaleza, comience a explotarla tanto material como estéticamente, ya sí de manera sistemática. Consciente de ello, el acercamiento del sujeto del poema a esta nueva realidad histórica parte, en primer lugar, de una óptica antropocéntrica. Así lo vemos en los primeros nueve versos del poema III de sus "CANCIONES EN PROSA":

1 Bajo las nubes rotas -que dejan ver desnudeces azulesestá la tribu de los ilotas contra la tierra. 


\author{
Mesnadas, gregaria pandilla, \\ olas y dunas de gentes: \\ es el sudor la única joya que brilla \\ por sobre el bronce. (De Greiff 1975: 201)
}

Como es ya habitual, el énfasis yace aquí sobre lo físico, sobre el hombre y su sudor, vistos ambos a través de "la tribu de los ilotas / contra la tierra" y de esa "única joya que brilla". Conocedor de que el término 'ilota' alude no solo a los esclavos del pueblo de los lacedemonios, ubicados al sur de la antigua Grecia, sino también a cualquier tipo de persona que "se halla o se considera desposeída de los derechos de ciudadano" (Real Academia Española, s.f.), De Greiff ya no se limita a concebir al país de Bolombolo como una síntesis escueta del colonialismo del medio oriente o el África. Apelando a una tradición heterogénea, el poeta recurre mejor esta vez a la historia de la Antigua Grecia para desde allí atestiguar el ensamble de todo ese aparato neocolonial instaurado por el proyecto modernizador. Pero justo cuando el poema pareciera agotarse en la esfera de lo humano, el noveno verso, a través de la mención del bronce, abre paso a la incorporación de la vitalidad orgánica del ecosistema anteriormente avizorada en el tono cobrizo de unas orillas rivereñas. Y, en este sentido, los aportes de Édouard Glissant (1989) podrían servir, ya que para el poeta y crítico literario martinico, esta movilidad, esta vitalidad, esta energía de la naturaleza se articula mayormente en narrativas [y nosotros agregaríamos 'poemas'] en donde "the landscape in the work stops being merely decorative or supportive and emerges as a full character. Describing landscape is not enough. The individual, the community, the land are inextricable in the process of creating history" (105-106, el subrayado es del autor).

Aunque hechas con base a un topos y una ontología de la existencia socio-histórica y cultural francocaribeña, las palabras de Glissant parecieran tener total resonancia en la poesía de De Greiff: cultura y naturaleza ya no son conceptos alejados. Al igual que en "FANFARRIA EN SOL MAYOR", la toma de conciencia en torno a la materia vibrante de la naturaleza abre paso a la explotación de la misma, pero da cabida también a un proceso de historización, quizá no abiertamente colectiva y/o comunal como la plantea Glissant, pero historización al fin y al cabo. Y, simultáneo a estos dos procesos, sirve también para formular un nuevo lenguaje poético, uno que recurre a la vitalidad orgánica del mundo natural, sin que ello suponga caer en las dinámicas representacionales propias del mimetismo. Insistimos por eso en que no estamos ya más ante un 'esmerilado cobre' imbricado en 'playas rutilantes', esperando a ser descubierto. De su carácter mineral, camuflado, invisible a los ojos y netamente constitutivo del suelo, el cobre ha pasado a ser parte ahora de una aleación metálica creada por el hombre - el bronce, visible a la mirada de todos; un bronce de un resplandor que solo es superado por el sudor de aquellos que excavan la tierra para luego usarle, venderle. Como bien escribe Enrique Foffani en un artículo sobre la economía política en Trilce de César Vallejo, lo que De Greiff deja al descubierto es "la incorporación por parte del discurso lírico latinoamericano de las materias primas de la Nación" (2014: 60), inclusión esta que figura no solo como "una tematización sino, sobre todo, como un procedimiento formal, que, operando por analogía, por alegoría o por antítesis, se deja ver a sí mismo, muestra su hechura, exhibe los materiales de su construcción" (2014: 60). Es precisamente la incorporación de ese gran cúmulo de recursos naturales lo que marca el punto de quiebre del poema greiffiano, ya que a partir de la tercera estrofa el hombre y la máquina habrán de alternarse con la existencia de una naturaleza cada vez más magullada por las políticas extractivistas:

10 Con agrio afán, la tribu, arando hora tras hora

canales hace en seco

para el agua en el humo de la locomotora

y la nave glisante por cintas gemelas.

Rompe la gleba intonsa, en iras;

15 mientras el ingeniero dispara ojos por diminutos

cañones, hacia banderolas y miras

bicromadas, y mide a zancazos ante mi indiferencia. (De Greiff 1975: 202)

Contaminación del aire, remoción de tierras ("rompe la gleba intonsa"), medición y cálculo, por un lado, y, por otro, desapego por la medición y el cálculo métrico de antes, polución lingüística y simbólica con base a nuevos referentes naturales. Más interesante todavía, el sujeto del poema, en un gesto de inexplicable nostalgia y derrota, pareciera querer insistir en que poeta y hombre de ciencia son diametralmente opuestos, que sus canales de domesticación del mundo natural difieren entre sí; que el uno no depende del otro. De ahí 
que la yuxtaposición entre una figura y otra no solo deba leerse como rechazo del quehacer violento del hombre de ciencia, sino también como afirmación de su maltrecho ego de artista:

Con traje de vaquero

y turbio plantaje de matamoro

20

gesticula el ingeniero

ante su cañoncillo de juguete,

que vuelve patas arriba

la flora y la fauna del paisaje

con intención lasciva:

25 lujurias transitorias....o taquimétricas... (De Greiff 1975: 202)

Violentación total de la flora y la fauna, pulsión dominante, decididamente sexual, del hombre con respecto a la naturaleza. Los versos no necesitan de glosa alguna; denuncian abiertamente el ecocidio de la década de los treinta en manos de las primeras exploraciones mineras en los que el rol de la máquina, en cuanto a síntesis del devenir tecnológico propio del siglo, jugó un papel fundamental. De cara a dicho panorama, el sujeto del poema se ve obligado a volcar nuevamente su mirada hacia ese Otro sobre el cual es posible reafirmar todavía su poderío, su superioridad:

\author{
Bajo las nubes rotas \\ -harapos maltapando carnes rica- \\ está la tribu de los ilotas \\ 28 contra la tierra. (De Greiff 1975: 202)
}

No obstante, una lectura más aguda de dicho cierre invita a sopesar la ambigüedad del mismo. Por un lado, pareciera que el sujeto del poema concibiese a las nubes, en tanto metonimia del cielo, como un harapo ultrajado, roto, afectado, capaces, no obstante, y desde arriba, como la posición que el verso mismo ocupa en la estrofa, de envolver las 'carnes ricas' de los obreros que abajo laboran. Pero, por otro, en una visión más consciente de la complejidad ecológica, pareciera que para este los verdaderos harapos fueran los ilotas, entes completamente escindidos de ese tejido ecosistémico, cuerpos ateridos que hacen lo posible por tapar, por cubrir esa savia orgánica, esas 'carnes ricas' y vitales, pero ya vapuleadas, que conforman el suelo sobre el cual trabajan.

En el contexto de este dominio y consecuente explotación de la naturaleza llevada a cabo por esta 'tribu de ilotas' colombianos de comienzos de siglo XX, los aportes hechos por la Escuela de Frankfurt, y más concretamente por el Theodor W. Adorno y el Max Horkheimer de la Dialéctica de la Ilustración, publicada por primera vez en 1945, resultan más que certeros. Ambos pensadores supieron entender que el avance irrefrenable tanto de la razón ilustrada como del flujo de capital habría de conducir de manera inexorable a la alienación no solo del hombre con respecto a la naturaleza, sino también del hombre con respecto a sí mismo. Aciertan, por ende, cuando señalan que:

Lo que los hombres quieren aprender de la naturaleza es servirse de ella para dominarla por completo, a ella y a los hombres. Ninguna otra cosa cuenta. Sin consideración para consigo misma, la Ilustración ha consumido hasta el último resto de su propia autoconciencia. Solo el pensamiento que se hace violencia a sí mismo es lo suficientemente duro para quebrar los mitos. (2009: 60)

Tal panorama nos pone ante el inicio del fin de la naturaleza: en el segundo poema-movimiento de FANTASIA EN SOL MAYOR, el poeta antioqueño recurre nuevamente al lenguaje y la dinámica musical, en este caso la fantasía, para con ello denotar cuán vulgar le resulta la actitud de los hombres de ciencia de comienzos de siglo frente a la naturaleza. El rótulo mismo de este movimiento, 'INTERMEZZO: SCHERZO ASSAI VIVACE", es decir, una especie de interludio de carácter vivaz y humorístico, en clave de mofa, condensa pues lo que para él es la actitud jocosa, ociosa, caprichosa, humillante salvaje e improvisadora de estos hombres:

1 Ahora

para hacer el camino a la locomotora

las lomas y los riscos disciplinaron:

las colinas, las abras, se tornaron

sabios cortes e insignes terraplenes, 


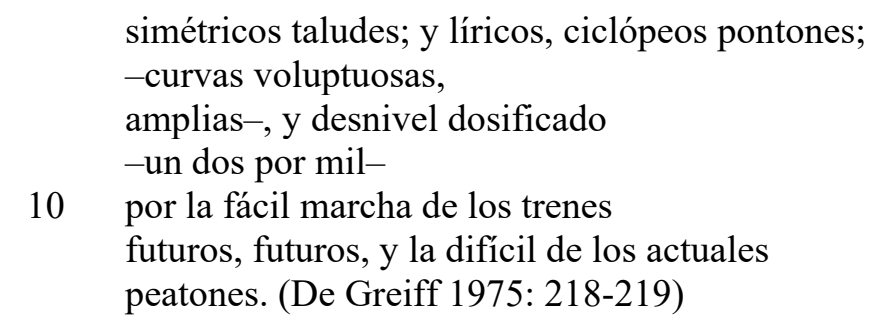

La antigua separación de planos paisajísticos visuales que vimos en FANFARRIA EN SOL MAYOR, que por un lado situaba a los picos, cerros y "horizontes cejijuntos", y por otro a trópicos, ríos y orillas, se borra aquí por completo. Tanto un plano como el otro han sucumbido ante el proyecto histórico de la modernización y el estético de la vanguardia. Nótese cómo el sujeto del poema, convencido también de que cualquier referente estético y estrictamente poético resulta ahora inútil para darle sentido al mundo que tiene ante sí, no escatima en el uso de vocablos matemáticos, científicos y maquinistas: 'taludes', 'pontones', 'rectas', 'tangentes', 'curvas', 'espirales', 'desnivel'. Su lenguaje es ahora el lenguaje del hombre moderno, del hombre de ciencia, del colono, del que explota, del que destruye naturaleza para luego construir 'cultura'. De ahí que la antigua división entre poeta e ingeniero que él mismo había trazado al comienzo de este poema, se diluya ahora por completo:

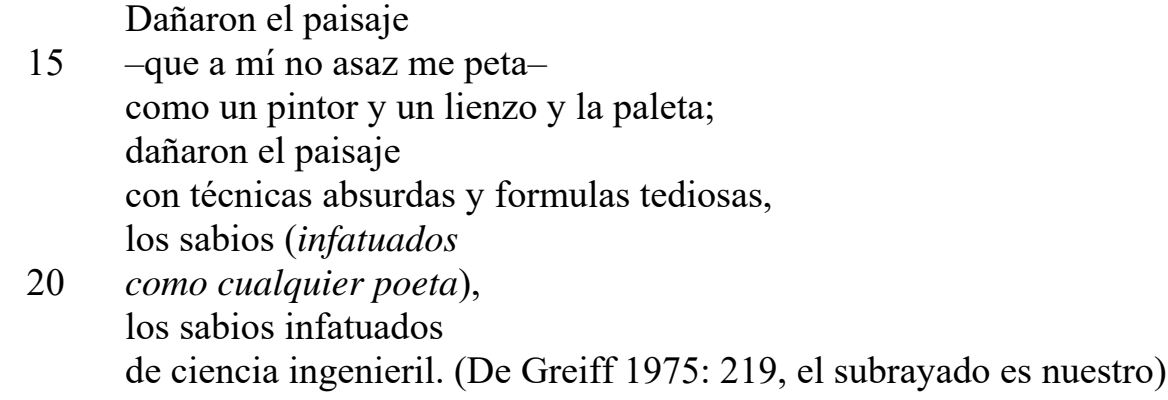

Poeta vanguardista e ingeniero son, pues, rostros de un mismo cuerpo, raíces de un mismo mito fundacional: poesía y ciencia como negación/destrucción/desencantamiento del mundo, pero también como afirmación/construcción, como fuerza motora; verso, estrofa, pico y pala como artífices de una 'violencia y un extremismo' que, según Octavio Paz, “enfrentan rápidamente al artista con los límites de su arte o su talento" (1985: 97). Por eso no es de extrañar que una poética mayoritariamente ecocéntrica como la que De Greiff nos ofrece, afirme y al mismo tiempo critique la dinámica antropocéntrica y por ende objetivante de la relación entre hombre y naturaleza.

En síntesis, el testimonio ecológico y ambiental greiffiano que hemos analizado acá, se podría resumir de la siguiente manera: el momento de encuentro entre hombre y naturaleza, al ser vista con actitud irónica, supone una total elisión de la barrera que separa la esfera de la cultura de la esfera de la naturaleza: ironía ante un hombre con ínfulas mesiánicas y redentoras, pero ironía también ante una naturaleza que precisamente por ser portadora de un dinamismo y una vitalidad que se excede a sí misma, impide, por lo menos en un comienzo, la concreción del proyecto tanto estético como histórico. De ahí que la ironía, que para el ya citado Octavio Paz es perteneciente "al tiempo histórico [y] es la consecuencia y la conciencia de la historia" (1985: 67), le permita a De Greiff presentar el quehacer poético mismo como testimonio fiel del intento de aprehensión y domesticación tanto estética como material del mundo natural por parte del hombre, como unificación total del mito fundacional histórico de la modernización y el estético de la vanguardia.

No obstante, esta última aprehensión, la estética, se muestra por un momento, pero solo por un momento, como imposible. Ante esta imposibilidad, el sujeto del poema se ve obligado a volcar su mirada sobre la vitalidad intrínseca de la naturaleza, a reconocer su valor. $\mathrm{Y}$ en lo que pareciera ser pues el fin del mito fundacional estético a manos el histórico, este reconocimiento del estatus ontológico de la naturaleza termina por reforzarlos más a ambos. El resultado: un hombre con total dominio sobre una naturaleza próxima a ser expoliada y vapuleada, y un nuevo tipo de poeta, el vanguardista, que, consciente de la vitalidad intrínseca de la naturaleza, logra ensamblar también todo un nuevo lenguaje poético a través del cual le será posible reclamar un total dominio sobre la misma. El poema greiffiano como historia de la violentación tanto material como simbólica de la naturaleza por parte del hombre, pero el poema greiffiano también como testimonio histórico de lo consciente que es él mismo con respecto a dicha violentación. 
A estas alturas se hace claro ya que, la Colombia de comienzos de siglo XX, al estar apuntalada por una cosmovisión judeocristiana y platónica del mundo que exacerbaba tanto sociopolítica como teológicamente los dualismos hombre/naturaleza, bien/mal, centro/periferia, blanco/negro-indio, civilización/barbarie, como también por una "modernización con expansión restringida del mercado, democratización para minorías, renovación de las ideas pero con baja eficacia en los procesos sociales" (García Canclini, 2001: 82), rápidamente observó cómo el proyecto de modernidad se vio rápidamente desplazado por un proyecto modernizador incipiente, vertiginoso, súbito y quizá por ende más brutal. Un desplazamiento de esta índole corrobora, entre otras cosas, que:

[...] mucho antes de que los de la Escuela de Frankfurt tematizaran el concepto de "razón instrumental", nuestros países [en este caso Colombia] tuv[o] una larga experiencia, y conciencia, de la instrumentalización como forma de racionalización moderna de la voracidad del capital, y ello mediante la implantación de una economía simbólica que, convertida después en desarrollismo, tornaría irracional toda diferencia no funcional a un desarrollo concebido como único (y último) vagón de la modernidad para Latinoamérica. (Barbero 2004: 118-119)

Como ejes centrales que eran de esta economía simbólica a la que alude Barbero, las múltiples y diversas ecologías nacionales se vieron fuertemente afectadas por el modelo primario exportador en torno al cual giraba toda la economía del país. El inventario se queda corto: deforestación, desvíos de ríos y quebradas, perforaciones, quemas, erosión, disposición inadecuada de residuos químicos, contaminación hídrica y atmosférica, desmonte y desestabilización de suelos, uso de pesticidas y herbicidas, desplazamiento de pueblos indígenas como también de especies marinas, terrestres y aéreas y, con ello, el desequilibrio total de la cadena trófica de dichos territorios. De ahí que una lectura ecocrítica de Libro de signos (1930) de León de Greiff como la que aquí hemos propuesto no hubiese tenido objetivo alguno más que el de incluir la temática de la violencia ecológica en Colombia en el tristemente amplio abanico de violencias sucesivas que ha experimentado el país desde el comienzo de su vida republicana.

El hecho cobra mayor relevancia todavía si tenemos en cuenta el carácter unidimensional y antropocéntrico que ha caracterizado a muchos de los estudios teóricos sobre la violencia en el país, los cuales, sin temor a caer en el esencialismo, parecieran limitarse al espeluznante, pero a la vez limitante espectáculo de la sangre. Conscientes de dicho monolitismo, críticos como Rob Nixon han llegado a la conclusión de que todos estos daños ecológicos, causados por las políticas de extractivismo de la modernización, y más recientemente por los diferentes actores del conflicto armado (léase ejército, paramilitares, guerrillas, multinacionales petroleras o mineras, entre otros) son constitutivos de un nuevo tipo de violencia, una violencia que él mismo ha tipificado como 'lenta'. Según Nixon, esta es una violencia que "occurs gradually and out of sight, a violence of delayed destruction that is dispersed across time and space, an attritional violence that is typically not viewed as violence at all" (2011: 3).

Visto desde este punto de vista, el afán del hombre colombiano de la década de los veinte y los treinta por querer apropiarse de la naturaleza y sus muchos recursos, puede y debe leerse entonces como una clara manifestación de violencia ecológica y ambiental, violencias estas cuya deuda, como bien lo pueden asegurar el estado actual de nuestro paramos, ríos, estuarios y cordilleras, "no solo es impagable, sino que es inconmensurable" (Leff, 2004: 35). Sin duda alguna, poemas como los aquí estudiados nos invitan a pensar en torno a las posibles maneras en que el discurso poético colombiano puede llegar a ofrecer una lectura de la violencia colombiana desde una óptica trans-humanista/trans-antropocéntrica en la que las diferentes ecologías colombianas y el medioambiente - y no solo el hombre - puedan ser integrados a esta lógica constructiva de la memoria, la reparación y la reconciliación.

\section{Referencias bibliográficas}

Ardila Ariza, Jineth (2013). Vanguardia y antivanguardia en la crítica y en las publicaciones culturalesccolombianas de los años veinte. Bogotá: Universidad Nacional de Colombia.

Barbero, Jesús Martín (2004), “Nuestra excéntrica y heterogénea modernidad”, Estudios Políticos, n” 25, pp. 115-134.

Bennett, Jane (2010). Vibrant Matter: A Political Ecology of Things. Durham, NC: Duke University Press.

Buell, Lawrence (1995). The Environmental Imagination: Thoreau, Nature Writing, and the Formation of American Culture. Cambridge, MA: The Belknap Press.

Charry Lara, Fernando (1984), “Los poetas de Los Nuevos”, Revista Iberoamericana, n 128-129, pp. 633-681. 
Corredor Martínez, Consuelo (1992). Los límites de la modernización. Bogotá: Ediciones ClNEP y Facultad de Ciencias Económicas de la Universidad Nacional.

De Greiff, León (1975). Obras completas I. Bogotá: Tercer Mundo.

Estripeaut-Bourjac, Marie (1999), "Los Nuevos como vanguardia: Lenguaje generacional, historia e imaginario", Thesaurus, Boletín del Instituto Caro y Cuervo, vol. 54, nº 3, pp. 729-773.

Foffani, Enrique (2014), "Poesía y economía política en Trilce, de César Vallejo, en el marco de las vanguardia latinoamericana", en Gladys Flores Heredia (ed.). Actas cel Congreso Internacional Vallejo Siempre. Octubre de 2014. Lima. Perú, pp. 60-75.

Gallo, Óscar y Jorge Márquez Valderrama (2011), “La silicosis o tisis de los mineros en Colombia. 1910-1960”, Salud Colectiva, vol. 7, $\mathrm{n}^{\circ}$ 1, pp. 35-51.

García Canclini, Néstor (2001). Culturas híbridas: Estrategias para entrar y salir de la modernidad. Buenos Aires: Paidós.

Glissant, Édouard (1989). Caribbean Discourse: Selected Essays. Trans. J. Michael Dash. Charlottesville: University Press of Virginia.

Handley, George B. (2010), “The Postcolonial Ecology of the New World Baroque: Alejo Carpentier's The Lost Steps”, en Elizabeth DeLoughrey y George B. Handley (eds.). Postcolonial Ecologies: Literatures of the Environment. New York: Oxford University Press, pp. 117-135.

Horkheimer, Max y Theodor W. Adorno (2009). Dialéctica de la Ilustración. Fragmentos filosóficos ( $9^{\mathrm{a}}$ ed.). Trad. Juan José Sánchez. Madrid: Editorial Trotta.

Jaramillo Vélez, Rubén (1998). Colombia: la modernidad postergada. Bogotá: Argumentos.

Latour, Bruno (1996), "On Actor-Network Theory: a few clarifications plus more than a few complications". Disponible en: http:/www.bruno-latour.fr/sites/default/files/P-67\%20ACTOR-NETWORK.pdf

Law, John (1994). Organising Modernity. Oxford: Blackwell.

Leff, Enrique (2004). Saber ambiental: Sustentabilidad, racionalidad, complejidad, poder.México D.F.: Siglo XXI editores.

Londoño C., Diana, Natalia González, Catalina J. Aristizábal y Juan Carlos López D. (2014), "De la Colonia a la República: colonizaciones, minería y comercio, 1780-1873”, en VV.AA. De caminos y autopistas: Historia de la infraestructura vial en Antioquia. Medellín: Gobernación de Antioquia y Universidad EAFIT, pp. 59-99.

Machado, Absalón (2001), "El café en Colombia a principios del siglo XX”, en Gabriel Misas Arango (ed.). Desarrollo económico y social en Colombia: siglo XX. Bogotá: Universidad Nacional de Colombia, pp. 77-97.

Mattos Omar, Joaquín, Amparo Murillo, Robinson Quintero y Luz Sierra (2010). Colombia en la poesía colombiana: los poemas cuentan la historia. Bogotá: Letra a Letra.

Molina, Luis Fernando (2011), “La 'industrialización’ de la minería de oro y plata en Colombia en el siglo XIX: sociedad de zancudo y compañía minera de Antioquia”, Revista Credencial Historia, nº 258, pp. 10-16.

Morin, Edgar (2008). El paradigma perdido: ensayo de bioantropología. Barcelona: Kairós.

Nixon, Rob (2011). Slow Violence and The Environmentalism of the Poor. Cambridge, MA: Harvard University Press.

Ostria, Mauricio (2011), "Literatura y ecología", Lecciones Doctorales, n 9. Medellín: Doctorado en Literatura, Facultad de Comunicaciones, Universidad de Antioquia.

Paz, Octavio (1985). Los hijos del limo / Vuelta. Medellín: La Oveja Negra.

Ramírez Rojas, Marco (2013). León de Greiff y la tradición literaria. (Tesis doctoral no publicada). Ottawa: Universidad de Ottawa.

Restrepo, Vicente (1979). Historia de las minas de oro y plata en Colombia. Medellín: Fondo Rotatorio de Publicaciones Faes.

Suárez Quirós, Jorge Andrés (2014), “La modernización de caminos y transportes, 1874-1929”, en VV.AA. De caminos y autopistas: Historia de la infraestructura vial en Antioquia. Gobernación de Antioquia y Universidad EAFIT, pp. 103-133. 